\title{
Las relaciones económicas internacionales del Brasil: notas para una agenda de investigación
}

Estas notas han sido organizadas de la siguiente manera: la primera parte procura situar los últimos acontecimientos acaecicios en el Brasil dentro de una perspectiva historica adecuada cle tal modo de dar la importancia que le corresponde a las cambiantes condiciones económicas del mundo de la postguerra. Elio se debe a que, a nuestro juicio, el análisis de un programil para el futuro carece cle sentido, a menos que se conozcan las limitaciones que impone a las opciones internas fundamentales la mayor integración clel Brasil con la economia internacional a través del comercio y, en especial, las finanzas y la inversión. Como no crecmos en el determinismo económico puro, la segunda parte procura abordar los temas del programa a parti: de un punto de vista que pone de relieve la función de la política (o cle la cconomía política), tanto en la reorganización prevista de la cconomía mundial y del marco institucional internacional como en los cambios que eventualmente habrian cle producirse dentro de países periféricos importantes, tales como el Brasil. Como esta discusión de politica económica tiene lugal" a la vez en los foros internacionales $y$ en los internos, se examinan brevemente los puntos cle vista del centro y de la periferia sobre el llamado confliclo norte-sur, que deben ser tenidos en cuenta en todo programa. La tercera parte presenta, a maneria de conclusión, una breve sintesis de los principales puntos de discusión planteados en estas notans preliminares.

Durante los últimos tres clecenios, con la fuerte contribución cle $\mathrm{ca}$ pital extranjero y la marcada y creciente participación del sector público en la vicla económica, la economía brasileña, pese a la inflación crónica y a los persistentes desequilibrios del balance de pagos, experimentó una de las transformaciones más rápidas y gene-

- Trabajo presentado en el Seminario soire "Perspectivas del desarrollo de los Estudios Latinamericanos Comparilos y las Relaciones Internacionales", Friburgo, Brasil, diciembre de 1977. Organizado por el Conjunto Universitario Cán. dido irendes. 
ralizadas de la estructura procluctiva que se haya visto en los paises seminclustrializados en que impera el llamado régimen de economín de mercado ${ }^{1}$.

De hecho, en la actualidacl se considera internacionalmente que el Brasil no sólo es una de las economias inclustriales más modernas y complejas del "mundo en clesarrollo", sino también una de las po. cas economias semiindustrializadas que al parecer han logrado realizar, con un grado razonable de éxito, la reconocidamente dilícil transición cle un clesarrollo industrial basado en la protección -posiblemente injustificada y muy crilicada- de las actividades del mercado interno a una etapa de desarrollo hacia afuera, basacla en cl incremento de las exportaciones no trad.cionales, en la "liberalizacrón" gradual del régimen de comercio exterior y en la creciente integración con los mercados internacionales de capital.

Esta transición debe verse en su perspectiváa histórica y a la lu\% de los cambios que là experimentaao la stluación cconómica munclial. Como se sabe, el períoclo de postguerra se camacterizó por la expansión asimétrica de las principales economías industriales $\%$ el impulso repentino que adquntió lai internacionalazición del capital bajo la égicla de las llamaclas empresas transnacionales 3 , el notabie cambio que sufrieron las modalidacles de comercio", las contradic-

2 En los últimos tres decenios ( 1945 a 1975 ), la tasa de crecimiento promedio del ingreso real al costo de los faclores ha sido de $7 \%$ al mo; este resultado só. lo se equiparará quizá al obtenido por el Japón a pátir de la segunda guerra mundial. En este periexlo el ingreso per cápita aumentó a unil tasa promedio de $4 \%$ al año en términos reales. Entre 1945 y 1975 el crecimiento industrial alcanzó una tasă promedio de $8.8 \%$ al año en términos reales, clevando la participatción de la industria en el ingreso al costo de los filctores de $20.8 \%$ en 1945 a $34.2 \%$ en 1975 (en cruceiros constantes a precios de 1970). La tasa anual de in. cremento del producto real de lia agriculutal entre 1945 y 1975 fue del orden de 5.6\%. Vease P. Malan y R. Bonelli, "The Brazilian Economy in the Seventies: Old and New Developments", World Development, vol. 5, No 1-2, 1977. pp. $19 \cdot 45$.

= Las tasas anuales promedio de incremento de la producción por Irora/hom. bre que se registraron de 1950 a 1970 en el Japón (9\%) y Nemania (6\%) fucron, resjectivamente, casi tres y dos veces superiores a las tasas anuales promedio de incremento en los Estados Unidos $(2.8 \%$ ) y el Reino Unido (3.2\%). Véase Departamento del irabajo de los Estados Unidos, estimaciones inćditas, citadas por R. I. Mckinnon en E. Classen y P. Salin (edis.), Stabilization Policics in Interdependent Economies (North-lolland, 1972, I. 22).

- Desde fines de los años sesental han aumentado progresivamente las publicaciones sobre esta materia. Véanse las distintas obras del profesor Raymond Vernon $y$ el Harrird Multinational Enterprise Study.

- La participación de los paises no pertenccientes a la ocor en las exportaciones mundiales disminuy de $34 \%$ en 1950 a $19 \%$ cn 1968 (cn este periodo la participación de $\Delta$ mérica Latiná se redujo de $10 \%$ a $5 \%$ ). La proporción de minufacturas en el comercio mundial aumentó de menos de $10 \%$ en los años treinta a $45 \%$ en $1953,54 \%$ en 1970 y $67 \%$ en 1968 , fenómeno que se relaciona unu estrechamente con las inversiones internacionales de las empresas multina- 
ciones intrinsecas clel arreglo institucional de Bretton-Woods, que en definitiva condujeron a su fracaso on agosto de 1971. La bonanza experimentada al mismo tiempo por las economias avanzadas en 1972 y 1973 contribuyó a alimentar la inflación más desastrosa que haya experimentado el mundo capitalista integrado ${ }^{5}$.

Ln vuelta de Europa a la plena convertibilidad, en 1959, accleró de manera espectacular algunas de estas tendencias. Por ejemplo, entre 1959/1961 y $1969 / 1971$, el comercio mundial aumentó a una tasa anual de casi $10 \%$ al año en dólares, y' de 1967 a 1973 al sorprendente ritmo de $18 \%$ al año ${ }^{\circ}$. Al parecer, no menos importante fue cl aliciente que dio la convertibiliclad a los movimientos de capital internacional privado. Estimulada por los déficit de balance de pagos cle los Estados Uniclos, la siluación monetaria en los años sesenta se caracterizó por la creciente importancia tanto en lo que toca a la composición de Jas reservas mundiales cuanto al incremento de la liquidez internacional, de los depósitos en las monedas nacionales de los principales países industriales, especialmente en clólares mantenidos fuera de los Estados Unidos i.

En realidad, las reservas mundiales aumentaron de 45.500 millones de dólares en 1949 a 78.200 millones de clólares en 1969 , lo que se tradujo en una tasa de incremento promedio de $2,75 \%$ al año en los dos clecenios. Issta tasa debería compararse con una tasa de aumento promedio anual de $22,7 \%$ de 1969 a 1974 (en que las reservas brutas llegaron a 217.900 millones de dólares estadounidenses), lo que representa un valor casi tres veces superior en el espacio de cinco años ${ }^{8}$. La utilización de las monedas nacionales de los países más ricos y capitalizados del mundo en caliclad de reservas internacionales representa $93 \%$ de la creación total de reservas en esos cin-

cionales y, con toda seguridad, con la conocida lipótesis del profesor Linder acerca de la influencia de los modelos de demanda $y$ los niveles de ingreso en la configuración del comercio entre los países desarrollados. Para datos básicos véase GaTT, International Trade, diversos numeros.

- Estos ferómenos han sido interpretados -y de hecho pronosticados-, entre otros, por eI profesor Robert Triffin. Véanse sus primeras obras Eutope and the Moncy Muddle (Yalc University Prcss, 1957). Gold and the Dollar Crisis (Yalc Unirersity Press, 1960) y cl trabajo más reciente, "International Monetary Collapse and Reconstruction in April 1972", Journal of International Economics, Vol. 2. No 4, septiembre de 1972 y "The Threat to World Econonic Order: the Wor'd 'Infession' and the Oil Explosion, versión mimeografiada American Enterprise Institutc, Abril 1075.

- Véase 1’ar, Inlcrnalional financial Slatislics, diversos númcros.

7 Este es otro campo en quic hay o hubo un aumento progresivo de las pu. blicaciones, tanto académicas como aplicadas. Como ilustración de las primeras, réase J. TVilliamson, "International Liquidity: A Survey", Economic Journal, scptiembre de 1973; respecto de las segthidas, v'́ase Litromoney, publicación que debe su aparición a! mercado de la curomoncda.

- Véase Intermational Financial Stalistics, diversos núlueros. 
co años ". Como señaló el profesor Robert Triffin, no hay cluda que este "sistema" cle creación cle rescrva cle créclito contribuyó para que los paises (avanzados) pudicran aumentar sus préstamos e inversiones en el tercer mundo. Como consecuencia de ello, el incremento dal excedentc global del balance cle pagos de los paises menos clesarrollados en esos cinco años (56.800 millones de dólares estaciounidenses) no se debe a los excedentes en cuenta corriente sino al sobrcfi. nanciamiento de sus déficit en cuenta corriente mediante importaciones de capital de los países desarrollaclos, especialmente de los Estados Unidos ${ }^{10}$.

No es la intención profunclizar en esta oportuniclad los orígenes y consecuencias de estos fenómenos, sino tan sólo observar que cles. cic el punto de vista cle la economía internacional, los últimos años clel decenio de 1960 y los primeros del de 1970 fueron más bien singulares, singularidad que hay que tener presente cuando se analiza el "éxito" de la creciente apcrtura cle la economía brasileña, tanto en lo que loca al comercio de productos básicos como a los movimientos de capital internacionales. En realiclad, pese a que el resurgimiento del comercio $y^{\prime}$ de las inversiones intemacionales en los años sesenta benefició fundamentalmente a las cconomias más avanzaclas, penetró hasta la periferia del sistema: paises cuya producción exportable complementaba la del centro y países semiindustrializados con niveles cle ingreso per cápila, relativamente altos, olerta de mano de -obra relativamente barata, políticas económicas bastante "sanas y cstables" y mercados internos amplios, crecientes y protegiclos.

Tradicionalmente, Brasil se ha beneficiaclo -o perjudicado, según los puntos de vista políticos de quien interprete la situaciónpor el atractivo que han ejercido en las inversiones extranjeras el tamaño clel mercado interno, la distribución asimétrica clel ingreso, los modelos occidentales de consumo urbano y' las prácticas protectoras. En realidad, en parte cleJjido a que tiene una de las legislaciones más favorables con relación al capital extranjero "1, "descle lá scgunda guerra mundial, las inversiones directas en el Brasil han alumentado más rápidamente que en ningún otro país cle América Lal'tino, salvo Venczuela. A fines de 1956, las inversiones directas estadounidenses en el Brasil sólo fueron superadas por sus inversiones en Canadá, ei Reino Unido y Venezuela" 12.

- Como lo denuestra el profesor R. Triffin en Euromoney, julio de 1975, p. 80.

${ }^{10}$ Piara una profundización de cstos puntos, vease R. Triffin, op. cil.

"Como lo reconoció el propio gobierno brasileño: "Lá legisjación brasileria es tradicionalmente una de las inás favoraloles del mundo con relacion a las inversioncs de capital extranjero", informe de la susoc (en la actualidad Banco Central), 1959, p. 37.

12 Véase U. S. Invesiments in Latin American Economy, Departamento de Comercio de los Estados Unidos, 1957, p. 64. Cabe obscrvar que Venczuela ocupa 
Lo más probable es que esta siluación haya cambiado, puesto que desde hace vartios años, desde fines del decenio de !1950, los Estados Unidos vienen realizando en Europa inversiones directas en gran escala. Lo que deseamos subrayar es que los ministros de economía del régimen que subió al poder en 1964 estaban plenamente conscientes del papel decisivo que habia desempeñado el capital extranjero en las reformas estructurales que tenían lugar en la cconomía brasileña. Por lo tanto, estaban clecididos a asegurar que continuara desempeñando este papel persiguiendo un desarrollo capitalista totalmonte aljierto ${ }^{13}$.

La creciente apertura de la economía brasileña a partir de mediaclos cle los años sesenta presenta dos aspectos: uno relacionado con el comercio de productos básicos y el otro con la afluencia neta de capital extranjero. En lo que se refiere al comercio, a través de simplificaciones burocráticas, de un complejo sistema de créditos $e$ incentivos tributarios y de la adopción en agosto cle 1968 de una política de minidevaluaciones, se logró trans[ormar cl sesgo contrario 1.4 a las exportaciones que éste mostraba en uno favorable a las ventas en el exterior que en el mercado interno ${ }^{15}$. Mrás bien de 1967 a 1973, las cxportaciones brasileñas aumentaron a razón de $24,8 \%$ al año, mientras que las exportaciones mundiales crecieron $18,3 \%$ al

el acreer lugar de la lista debido a liıs inversiones del petrólco. Más de la mitacl de los 1.200 millones de dólares estadounidenses invertidos en Brasil se cncontraban en el sector manufacturcro (701 millones de dúlares estidouniclenses) . La cifra comparable para Venczuela fue de 114 millones de cloblares csiadounidenises.

1s Pese a lin defensa del sector privado qlie lícieron los sucesivos gobiernos, Ja intervención del sector púlslico en la vida económica, a la vez como claborador de polliticas y como productor directo a través de empresas estatalcs, aumentó después de 1964. Este es uno de los campos de investigación más atrajentes cn materin de polftica cconómica en el Brasil.

"Que entre $1917 \mathrm{y}$ ] 1964 han fluctuacio entre 1.100 millones de dólares estalklomidenses (1949) $y$ i 1.771 millones de doblares estitiounidenses (1951, nivel más alto linsta 1968), con un promeclio de 1.448 millones de dólares estadounidenscs. E 11 realidad, uno de los asjectos más notiables de la experiencia brasileña de desarrollo económico fue altcanzar una tasa promedio de crecimiento del producto interno bruto en términos reales de $7 \%$ en dos decenios consccutivos (19471967 ), cn que las cxportaciones estuvicron pricticamente paral'zadas (cntre 1947) 48 y $1967 / 68$ la tasa anual de incremento en clólares fue de só́lo $2.1 \%$, cifra inferior a li tasa de aumento de la población). La capacidad de importación también se paralizo, ya que durante el perfodo no bajaron los precios de las importaciones.

is Véase C. Vou Doellinger y otros, Transformaçao da Estruclura das Exporlacaoes Brasileiras: 196+1970, iNPes/Irel, Informe de Investigación No 14, 1973, y A Polltica Brasileira de Comercio Exterior c Seus Efeitos 1967-1973; INPES/ liba, Informe de inyestigación No 22, 197. Véase asimismo W. G. Tyler, Mamuactured Export Expansion and Industrialization in Brazil, Institut fur Telt. wirtscha[t, Uniyedsidad de Kic], 1973, en especial el capitulo 7. 
año. Como los precios cle las exportaciones subieron más que los cle las importaciones (un promedio de 9,4:\% al año en contraposición a $6,2 \%$ de aquéllos de las importaciones), la relación de intercambio creció $20 \%$ cntre 1967 y 1973, y permilió que el ingreso allmentara at una tasa superior a la del producto. Debiclo a que las exportaciones aumentaron en $13 \%$ al año, entre 1967 y 1973 la capacidad corriente de importar se incrementó en un $150 \%$, lo que constiluje el incremento sosteniclo más marcado que haya experimentaclo el Brasil descle los años veinte.

Esta creciente capacidad de importar se utilizó más que plena. mente. Ello era de esperar, puesto que en una economía semiinclustrializada en crecimiento las importaciones tienen que aumentar a un ritmo levemente superior al de las exportaciones para asegural la muy necesaria transferencia de recursos renles del resto del mun. do. En realidad, entre 1967 y 1973 las importaciones brasileñas (cif) acusaron un incremento de $27 \%$ al año, mientras que las importaciones mundiales aumentaron $17,5 \%$ al año. La descomposición de este incremento cn sus componentes de precio y cantidad indica que cl quántum importado aumentó $18,5 \%$ al año en el periodo, mientras que los precios de las importaciones aumentaron a un ritmo tres veccs inferior $(6,2 \%)$. La elasticidad-ingreso inplicita de la clemanda de importaciones reales - casi 2- cemuestra la validez de la crucial observación formulada por Diaz-Alejandro:

"Ten:endo en cuentá los márgenes de crecimiento dentro de los cuales un pais ha creado industrias de bienes de consumo $c$ intermedios pero aún no lia desarrollado cle manera significativa la inclustria de bienes de capital, mientras mayor sea la tasa cle crecimiento del ingreso per cápila, más probabilidades habrá de que si propensión marginal a corto plazo para importar sea proporcionalmente major a su propensión pronedio para importar debiclo a su dependencia de los bienes de capital importildos y a la naturalezal cíclica de la demanda de estos bienes" 16 .

En rcalidad, las importaciones de bienes de capital, que en et periodo 1965-1966 representaron poco más de un cuarto de los gastos por concepto de inportaciones, llegaron a $4.1 \%$ de las importaciones totales en el periodo de 1971-1972 ${ }^{17}$.

10 C. Diat-Alejandro, On the Import Intensity of Import Sulstitution, Kyklos, 1965 , p. 509 (subrayado nuestro). IStaz ticnc la precaución de observar que csto to tiene que confundirse con el distingo cntre la clasticidacl-ingreso a corto plizo de la demanda de importaciones, en que la primera jarte da la base de unal calpacidad productivil determinada $y$ la segunda da margen a variacioncs tanto de la demanda interna como de las condiciones de la oferta.

${ }_{27}$ Cabe señalar que los datos que acaba te publicar cucex (Carteira de Comercio Exterior) del Banco do Brasil, y que señalan la descomposición de las importaciones de bienes de capital por ścetores de dewanda en el decenio comprendido entre $1904 \mathrm{y} 1974$ efectivamente revelan un aspecto notable del caso 
Jista elevadisima tasa de acumulación de capital (ya que entre 1967 y 1973 la producción interna de bienes de capital aumentó en promedio ell la impresionante cifra de $20,5 \%$ al año) se alcan\%ó simultáneamente con tasas muy altas de incremento de los gastos en consumo. In combinación de un gran esfuerzo de jnversión con una alta propensión a consumir sólo fue viable a través de uma política de aumento-acelerado del encleuclamiento externo ${ }^{18}$. Como se observó, el panorama internacional permitía seguir ese camino ${ }^{19}$. Por lo tanto, entre 1967 y 1973 la deuda cxterna total del Brasil casi se carachuplicó (aumentó de 3.300 millones de dólares a 12.600 millones de clólares) ${ }^{20}$ y lo que es más importante, en 1973 , los préstamos monetarios, que en 1967 sólo representaron el 20\% de la deuda total, llegaron a constituir casi clos tercios $(62,4 \%$ o 7.850 millones de dólaves) de la deuda cotal, ammentando a una tasa promedio de más de 50\% al iño entre 1969 y $1973^{22}$. Este incremento se debió en parte a los sucesos mundiales antes señalados y en parte al proceso de adopción de decisiones en el Brasil, que se basa íntegramente en

brasileño: cosi la mitad (proporción que se manticne eslible) de las importa. cioncs van a sectores tales como los de energia eléctricil y transjorte y comunicaciones, que se caracterizan por la predominante participación del seclor pii. blico $y$ por el hecho de que son actividades intcrnas (no comerciales). Esto plantea problemas intercsantes para futuras investigaciones. Para los datos brísicos, véasc cacex, Relatorio Anual, 1973 y 1974 .

28 ,Esto no quicre clecir que el Brasil simplemente necesitara cierto volumen de "ahorro cxterno" para "complemelltar" su ahorro inlerno para cl financia. miento de altos nireles de gasto en consumo e inversión. Para una crílica de esta intcrpretación simpl'sta del caso brasileño $y^{\prime}$ el piantcamiento de uma hipó. tesis altemativa, véase $P$. Malan $y \mathrm{~J}$. T $W^{\top}$ clls, "Enclividamento Externo, etc.: Uma Nota para Jiscussao", estudos crbrar, No 6, octubre al dicicmbrc de 1973. Este articulo incliat hasta que punto el ahorro interno del Brasil tienc "clisticidacl inst'tucional".

10 Para un cuidadoso andlisis de cste problema descic un punco de visła más amplio, véise J. TWells, "Euro-Dollars, Foreign lJebt and the Brazilian Boom", Torking papel No 13, Centro de Estadios Latinoamericanos, Universidad de Cambridge, octubre de 1973.

3' Deste la Segundat Guerm Mundial hasta 1060 el total de la cleudid externa brasileña se mintuvo pricticamente invariable en tomo a un promedio cle 1.900 millones de dólares.

Entre 1960 y 1904 alumentó de 1.955 millones de dólares a 2.700 millones de dólares estadoninidenses, lo glte exigió su rencgociación por el golsicrno de Castclo Branco.

- Esto se tradujo en un proceso singular en que sillulláneanente alunentó Iit deutia externil y mejoró la posición del Brasil en malteria de reservas internacionales, las que en 1973 liegnron a un máximo alusoluto de 0.400 millones de dólares.

los problemas de administación cconómica que curraña neutalizar esıe atımento de las reservis increcerfan un estudio especial, sobre todo por lis repercusiones que la tenido impllcitamente en materia de distribución. Véase P. Mralin $y \mathrm{~J}$. Wells, op. cil. 
la maximización a corto plazo de la tasa de crecimiento del producto interno bruto.

Estudios recientes indican que en el perfodo comprendido entre 1968 y 1973 este objetivo pudo alcanzarse en parte clebido a los elevados niveles cle capacidad ociosa existente gracias a la acumulación cle capital en períodos anteriores. En la actualidad ya se sabe bastante bien hasta qué punto este comportamiento dependió de la situación económica internacional de ese perlodo determinado. No pretenclemos negar el papel que desempeñó la polftica cconómica para ayuclar a materializar la polencialidacl de crecimiento que existía en 1967, pero estamos persuadidos de que la política se ha aplicado demasiaclo tiempo, perdurando más allá de su utilidad y contribuyendo a los graves desequilibrios observados a partir cle 1974 , y que se agravaroin seriamente a raíz de la crisis del petrólco.

En más de un sentido, el año 1974 debc considcrarse como un punto de referencia importante en la evolución de la economía brasileña. Por desgracia, las interpretaciones oficiales y semioficiales han puesto demasiado énfasis en los efectos de la cuadruplicación de los precios del petróleo. Es efectivo que el Brasil sólo produce alrededor cle $20 \%$ del total de petróleo que consume. También es cierto que el alza de los precios del petróleo modificó de manera espectacular. y desfavorable la relación de intercambio del Brasil e inlluyó de mancra negativa en el ingreso real disponible. Más importante quizás, cs el hecho de que la crisis clel petróleo ha puesto de manifiesto $\mathrm{cl}$ alto costo social que lleva envuelta una modalidacl de iso de los recursos que, en el caso de un producto que es escaso en el país, exige un alto coeficiente de éste y, por lo tanto, a largo plazo genera graves problemas. Sin embargo, debería ser obvio que éslos van más allá del manejo de perturbaciones de corto plazo del balance cle pagos. Asimismo, en cierto modo ern ingenuo esperar que si no Inubiese sido por la decisión adoptacla por la oper el Brasil podría haber continuado su "milagro económico" hasta fincs clel clecenio 22.

No obstante, a estas alturas es evidente que la duplicación con creces de los gastos por concepto de importaciones en 1974 y el cléficit implícito de 4.600 millones del balance conercial (las exportaciones aumentaron en $28 \%$ ) no podian atribuirse exclusivamente a

= Vénse proyecto do II Plano Nacional de Desenvolvimiento: 1975-1979, Brasilia, cn especial las pilgs. 23 y 67 . En renlidad, pesc 2 algunas abscrvaciones Icvemente cautelosas sobre dificultacles futuras, las proyecciones del plan incluirán lasas de crecimicnto del producto interno bruto de $10 \%$ a! año hasta 1979 , de incremento de las exportaciones ligeramente superior a $20 \%$ al año, aumento (le las importaciones ligeramente inferior a $20 \%$ al ano, una lasa (implicita) de inflación de alrededor de $15 \%$ para 1975 , y una tasa de creciniento anual promedio del consumo personal de $9.2 \%$, en términos reales, hasta 1979 . 
los precios del petróleo. La tasa de aumento de las importaciones de $102 \%$ se descompone, en $51 \%$ por concepto de numento de los precios y en $34 \%$ correspondiente al incremento históricamente alto del volumen importaclo (en especial metales básicos, bienes de capital, productos químicos y productos cle acero). Excluido el petróleo, el inclice de volumen acusó un incremento superior al inclice de precios ${ }^{23}$. En síntesis, la cuadruplicación de los precios del petróleo no podria haber explicado la totalidad clel desequilibrio. No hay duda que la recesión que experimentaron las economías capitalistas avanzadas en 1974 y 1975 (la tasa de crecimiento renl del producto interno bruto alcanzó un valor negrativo cle $2,1 \%$ para la región cle ha OCDE) ${ }^{24}$, y cl cambio cle modalidad de comercio que va unido al esfuerzo de los países clesarrollaclos por financiar con más exportaciones el aumento de sus gastos por concepto de importaciones 25 tendría que influir en las posibiliclades de que la economía brasileña pudiese resolver su problema de balance de pagos aumentandlo las exportaciones y disminuyendo las importaciones.

Como sc sabe, el superávit de los países de la orep (67.000,43.000 y 39.000 millones de dólares, respectivamente, en 1974, 1975 y 1976) fue el déficit del resto del mundo. Como las economins avanzadas lograron trasladar bastante rápidamente la carga del déficit a través de excedentes de exportaciones, los países en clesarrollo no productores de petróleo tuvieron que soportar una carga clesproporcionacla. En realidad, los déficit en cuenta corriente cle estos paises (incluidas las transferencias oficiales) aumentaron de 2.500 millones de clólares en 1973 a 17.500 millones en 1974 y a 27.000 millones en $1975^{28}$. La magnitud del déficit brisileño (aproximndamente 7.000 millones de dólares en 1974 y 1975 y 6.000 millones en 1976) comparado con estas cifrns, que se refieren a ochenta o noventa países

2 Es cfectivo que en 197.1 el costo en livisas de las importaciones de petróleo fuc superior ell dos mil millones de coúlares al del año aluterior. Sin cinbar. go, cabe señalar que tan sólo 115 empresns trausnacionales que operan en el Brasil obtuvicron autorización para importar $3 \mathrm{mil}$ millones de clólares. Como sus exportaciones fueron inferiores a 900 millones de clólares, el tléf cit comercial de poco más de cien empresas llegó a cnsi 2 mil millones de dólares de un tolal de 4.600 millones de dóln res. Vénse Jomal do Brnsil, 30 de inayo de 1976.

- Como observa la ocne, "Lanto en la ctaju de expansión que se cxtendió de 1972-1973 como en la de recesión de 1974-1975 se olsserva uni notable siucronización entre los patscs grandes". V'énse Perspectives Ecomomiques de l'ocne, $N^{\text {To }}$ 17, julio de 1975, p. 8 .

I Esfuerzo que ha resultado muy fructfero: en 1074 las importaciones de los paises de la $\operatorname{OCDE}$ aumentaron sólo $1.5 \%$ y en 1975 disminuyeron $9.5 \%$. Sus exportaciones aumentaron $75 \%$ en 1974 y disminty'eron sólo $5.5 \%$ en 1975 . Lo qute es mós importante, las exportaciones de la ocoe a los países de la orep altmentaron $42 \%$ en 1974 y $18 \%$ en 1975 . Véase ocne, Economic Ditlook, $N^{\circ} 18$, diciemlre de 1975.

so Véasc OCDE, liconomic Outlook, N' 18, p. 11. 
"en desarrollo", expresa muy bien tanto las dimensiones como la singularidad del problema brasileño, que no puede explicarse por la simple mención de una "crisis internacional" general.

El hecho es que en los últimos cuatro años (1974 a 1977) la economia brasileña ha acumulado un deficit en cuenta corriente cercano a 24.000 millones de dólares, alrecledor de 10.000 millones por cléficit de comercio, 7 a 8.000 millones por el pago de intereses brutos sobre la deuda externa. Estos 24.000 millones tuvieron que linanciarse a través de la cuenta de capital (y pérclicla cle reservas en el período de 1974 a 1975), con lo que el total cle la deuda externa aumentó de 12.600 millones de dólares en 1973 aproximadamente 31.000 millones en 1977. Los defficit en cuenta corriente de esta mianitud (en promedio cerca de $6 \%$ del producto interno bruto) reflejan al mismo tiempo: a) un nivel de gastos públicos y privaclos, en consumo e inversión demasiado alto en relación con la capacidad productiva interna ${ }^{27}$ (a precios dados) y, lo que es más importan(e; b) una composición del total de gastos y, por lo tanto, un modelo de distribución del ingreso que no puedc mantenerse con la capacidacl existente 28 .

Descle 1974 el gobierno ha tratado de evitar las dilfciles opciones que plantea el cambiar la tasa y composición de los gastos sin definir claramente ias prioridacles. Se ha procuraclo simultáneamente aumentar los gastos on servicios sociales e infraestiuctura y estimular las inversiones privadas en las actividades de sustitución de las importaciones. En realidad, muchos círculos gubernamentales piensan que estas últimas son el sistema de largo plazo para superar los clcsequilibrios recurrentes del balance de pagos que Brasil siempre ha tenido que confrontar después de periodos de crecimiento acelerado. Hace casi dos años, comentando los ambiciosos programas de inversión y las estimaciones del gobierno, expresamos:

"Es muy posible que la estrategia que consiste en tratar de hacer demasiado sin contar con un conjunto bien definiclo de prioridacles sea contraproducente. Aunque muy necesarias, porque hasta ahora se han quedado muy rezagadas, las inversiones en servicios sociales y programas de infraestructura (que

T Como nos recordó háce mucho el profesor Sivan “...no existe, ni siquiera a corto plazo, medida alguna que sustituya a lia liminción efectiva cle los gastos a) nivel de bicnes y servicios disponibles, producidos en cond"ciones de pleno empleo, sumado el excedente udximo de importaciones que podellos permitirnos mucho después de haber pernitido una disminnción transitotia de las reservas". T. 'V. Swm, "Jonger Run ''roblems in the Balance of Pilyments", en R. Claves y H. Johnson (cditors), ALA Readings in Intemational Economics (Richard Irwin, 1968), p. 460.

- Véuse R. Cooper, "Currency Dewaluation in Developing Countries", Essaj's in International Finance, $\mathrm{N}^{\prime}$ 86, Princeton, 1971, p. 20. 
tarclan mucho en mostrar sus frutos) se disputan los recursos escasos con las inversiones en las actividacles de comercio internacional (las que producen bienes exportables o que compiten con las importaciones, o ambas cosas). Es muy posible que el intento de estimular simultáneamente ambos conjuntos de activiclacles, en circunstancias en que declina la tasa cle crecimiento y que no se pucde recurrir libremente a las fucntes externas de abastecimiento, velva a agravar la inflación, como ha sucediclo tan a menudo en el pasaclo, y' exija mermas selectivas de Jos gasios para aliviar las presiones inflacionarias provenientes de la clemanda" 20 .

En más de un sentido, la predicción cstá resultanclo exacta. Sin embargo, para los efectos del presente artículo, lo que hay que clestacar, clejanclo cle laclo mi opinión personal, es que la solución "natural" para adaptarse al clesequilibrio es clar prioriclacl al sector cle la cconomia "vinculado al comercio" en lo que toca a la asignación de recursos reales y financieros escasos. Al respecto, no basta con las inversiones del sector público. Mucho depende de la tasa de inversion privada, en especial de las empresas de propiedad extranjera que, según las mejores estimaciones disponibles, actualmente mantienen casi un tercio del capital del sector manufacturcro. Esta proporción es mayor justamente en aquellos sectores en que el gobierno clescaria estimular una mayor sustitución cle las importaciones, y alcanza casi a $50 \%$ en el sector cle bienes cie capital 30.

Por lo tanto, y por irónico que parczca, es muy posible que lo que algunos han considcrado una oportunidad única de cambiar el "modelo brasileño" (en el sentido de consumo en grälı escalá de lá producción de las industrias "tradicionales" y en el énfasis en el "mercaclo interno") en definitiva bien puede no lacer más que fortalecer las líneas generales del "modelo" que sc ha cstado desarrollando descle los años cincuenta: aumento de las inversiones públicas y manejo de incentivos para incrementar la rentaljilidad privada de los sectores "dinámicos", que son aquellos en que predlomina el capital extranjero debiclo al control de la variable clave, Ia tecnología. No cxistiendo grandes cambios en la coalición política, la creciente "internacionalización" de la economia brasileña, con toclo lo que entraña para las modalidades de consumo, la composición de la producción y otros elementos menos tangibles, parece ser un hecho al que un mayor número de brasileños tendrán que habituarse más en los próximos años. Como dice muy apropiadamente L. Taylor ${ }^{31}$,

to Vease P. Malan, "The Brazilian Econony, 1975 and after: The major issucs at stage", documento inéclito, IPEA/INIPS, encro de 1970, p. 4.

a) Para mayores detalles, vease P. Malan y R. Boncli, op. cit.

"Vease L. 'Taylor, "Short-Tern Policy' in Open Dereloping Economies: The 
lo más probable es que "los cstrechos límites cle lo posible" se hagan valer con especial fuerza en las actuales circunstancias.

Estos límites estrechos de lo posible no sólo se aplican al Brasil. Tampoco son límites impuestos exclusivamente por las estructurals o dispositivos económicos. Para definir estos límiles tal vee sean mucho más importantes los procesos politicos cle identificación de lo que el Profcsor Hirschman clenominó los problemas "apremiantes" que clebe aborclar la política pública 32. Este proceso político es a la vez mundial (tiene lugat en foros internacionales tales como las $\mathrm{Nit}$ ciones Unidas, la unctad, las reuniones de la Conferencia de Cooperación Económica Intcrnacional y' todas las clemás conferencias en que se analizan los problemas clel llamado conflicto norte-sur) e interno (en el cual el temario de los problemars importantes y de sus soluciones optativas es un objeto natural de controversias, en el que interviene el Lstado y que éste examina).

En la presente sección se procura analizar las cuestiones importantes que van enrueltas en la estructuración cle un eventual nuevo orden económico internacional a partir de dos puntos de vistä: IEl primero, es el de los paises centrales, es decir, lo que signilica para ellos la reorganización de la economía mundial y sus criterios dominantes, probables reacciones y principales opciones en el denominnclo conflicto norte-sur. Estamos convencidos de que en el brasil estos sucesos deberian ser objeto de muchísina más atención de lo que han sido hasta ahora. El segundo, son los efectos - y lat reacción- ocasionaclos en los paises periféricos (en especial los principales tales como el Brasil) por las decisiones politicas y económicas (o la falta cle ellas) de los países aranzados. Los párrafos siguientes tratan de estos puntos cle vistat a partir del criterio de las economías centrales. No son muy tranquilizadores debido a la actual fragmentación del pocler. Sin embargo, como sostenchremos más adelante, esto tiene venlajas e inconvenientes.

Las economias centrales han aplicado con éxito una politica de negligencia benevolente con relación a la crltica que formulan los países en desarrollo de que el antiguo orclen cconómico intemacional Ios perjudica.

Las primeras publicaciones cle la Comisión Económica para América Latina, la Conferencia de Banclung en 1955, e incluso la crea-

Narrow Jinits of the Possible", Journal of Development Economics, vol. 1, 197.

$\approx A$. O. Hirschman, "Policymaling and Policy Analysis in Latin America $-A$ keturn Journey", Policy Sciences, 6, 1975, en especinl las pitginas 388 a 394. 
ción de la UNCrAD en 1964. (y el pripel que ha desempeñado descle entonces) fueron considerados como un despliegue de balbuceos politicos ineficnces condimentado con un poco de mala economía y envuelto en mera jerga retórica. EI [räicaso del arreglo de Bretton Woods en 1971-1972, seguiclo muy Juego, en 1973-74, por la exitosa afirmación por parte de la opep de su influencia en el mercado y la adopción hace justo tres años de una carta de derechos y cleberes económicos de los Estados por la Asamblea Gencral de las Naciones Uniclas (con su llamamiento a un Nuevo Orden Económico Internacional) dio un ruelco espectacular a la situación e indujo a los países avanzacios a convenir en iniciar conversaciones serias.

Por el momento, el resultado de estas conversaciones es imprevisible. El liracaso de la reunión cle clieciocho meses que tuvo la Conferencia de Cooperación Eiconómica lnternacional en P'aris en .1976, no fue un resultado delinitivo. Se programó una muportante reunión die la UNClito para comienzos de 1978 cn que - una vez más- se debatirá el impresionante conjunto de cuestiones económicals que conliguran el temario del diálogo norte-sur: las tendencias y opciones del actual sistema intemaciona!, de intercambios de la perspectiva de la inversión extranjera directa, la cleuda externa de los paises en desarrollo menos aclelantaclos, los precios de los productos básicos, la polsreza del llamado cuarto munclo y el sistemia moneturio internacional que el munclo aún no ha adoptado. Mucho depencle de la respuesta que den los paises centrales a las exigencias, aún relalivamente desarticuladas, de los países menos desarrollaclos. Sin embargo, los problemas y criticas planteaclas hasta ahora no se harán humo; lo más probable es que sigran figurando en el temario económico y' político durante muchos arios. Pocos discutirian que en la actualiclad atravesamos por un períado de crisis -económica e institucional- en que es muy probable que se marque un punto clecisivo en la historiá.

Por curioso que parezca, lo que más há chocaclo a los representantes de las economías centrales en los debates internacionales es lo que considernn una inconveniente y cxcesiva politización cle las cuestiones en juego ${ }^{33}$. Sin cmbargo, los estudiosos que tienen algún sentido de la historia distinguen entre dos planos de análisis: "uno de proceso, que se ocupa del comportamiento de corto plazo dentro de un conjunto constante de instituciones, supuestos fundamentales y expectativas; $y$ uno de estructura relacionado con las determinan-

* Viase, por ejcmplo, N. Lef, "The New Economic Order - Bad Econom:cs Worse Politics", Foreigh Policy, 24 le noviembre, tercer trimestre de 1970. Para uma reseña más imparcial, vénsc el priıner volumen lel Proyceto para los años ochenta del Consejo de relaciones exicriores: F. Hirsch, M. Doyle y E. L. Morse, Allernatives to Monetary Disorder, Mc Graw-Hili, $197 \%$. 
tes polílicas y económicas de largo plazo de los incentivos y' limitaciones sistemáticas dentro de los cualcs actúan los factores ... Es probable que la controversia y, por lo tanto, la politización, aumenten más rípiclamente cuando se ponen en tein de juicio las estructuras aceptadas $y$ las reglas clel juego... llegan a predominar las interrogantes relativas a quién ejercerá el control politico $y^{\prime}$ de qué manera" 34. Lin realiclad, por desalentador que pueda parecer hasta ahora, la controversia sobre el Nuevo Orden Económico Internacional ha centrado marcadamente la atcnción del mundo en la necesidad de reexaminar los principios políticos implícitos y las reglas clel jucgo cxistentes (y ausentes). No es algo que pueda pretenclerse que se resuelva en pocos años, particularmente si se piensi que aún no hay acuercio sobre un programa de acción, ni siquiera clentro de los pallses centrales presuntamente amenazaclos.

En realidad, es probable que la reacción de los paises centrales a las presiones de los países menos clesarrolladios vay'a evolucionancio de acucrdo con las siguientes pautas (que no son recíprocamente excluy'entes) : a) resistencia (en todos aquellos casos en que resulte fácil recinazar el desafío de los países menos desarrollaclos; b) coopción (en la cual quizá delsan participar los páses menos desarrollados principales y cle mayores ingresos) ${ }^{3 \sigma}$ y c) transacción (cuanclo haya que hacer algunas concesiones para que las economfas centrales pucdan mantener el control de las decisiones bísicas). Sin embargo, muchisimo más importante que adivinar las posibles reacciones del no:tc es evaluar cl criterio que predomina en cstas socicclacles, en especial en los Estados Unidos que, pese a que su importancia va en descenso (en comparación con los primcros años de la postguerra) sigue siendo el pás clave que influye en el resultado futuro del conflicto norte-sur.

Al parecer, en el centro hay cuatro puntos de vista clominantes sobre las cuestiones relacionadas con este conflicto. Según el primcro, expuesto por Roger Hansen, la "Unidad del Sur no perdurara" ia.

at C. F. Bergsten, R. O. Keohane Y J. S. Nye, "International Economics and Intemat:onal Politics: a Framework for Analysis", en C. F. Bergsten y L. B. Krause (cditores). World l'olitics and Inlernational Economics, Brookings Institution, W'ashington, 1975, prig. 5 a 6.

* A manera de testimonio puede citarse la ampliación del Grupo de los Diez para fornar Grupo de los Veinte, elel Fondo Monetario Internacional, la sugerenc'a de que se invite a! Brasil $y^{\prime}$ is Irán a incorporarse a In OCDE, $y$ asi sucesivamente. (La sugerencia fue formulada por C. li. Bergsten en L. Bhagwatli (ed.) The New International Economic Order, Editorial del MIT, 1977.

an Vease R. Hansen, "Major U. S. Options on North-South Relations: A Letler to I'resident Carter" en The Uniled States and I'orld Development - Ager. da 1977, por J. Seweil y los funcionarios icl Overseas Development Council, l'racger, 1977, pág. 25. Los próxinos pírnafos están fuertemente influidos po: este interesante menorándum de "acción". 
No hay duda de que eso exa lo que esperaban los principales países industriales (en especial los Istados Unidos). Dicho criterio sigue tenienclo mucha influencia. El primer revés importante se produjo cuando no se logró poner a los países en desarrollo no productores de petróleo, en contra de los exportadores de petróleo, poco después de la primera vez que la OPEP alzara espectacularmente los precios. El segundo, cuando la OPEP y todos los países menos desarrollados rehusaron limitax la Conferencia de París a una discusión de los problemas energéticos exclusivamente. Sin embargo, este criterio sigue muy vigente y no podría descartarse. ¿Qué tienen en común Brasil, Alto Volta, Sri Lanka e Irak? Quizá tan sólo que comparten la sensación de estar postergados frente a los países de la ocos. Pero como recuerda con toda razón $R$. Hansen (o, mejor dicho, el Presiclente Carter) no hay que subestimar esta "alianza antinatural", "especialmente confrontados a la intransigente solidaridad del norte... y" si no se juega ninguna otra carta en la mesa cle negociaciones" "3i. Los sucesos de los últimos tres años efectivamente inclican que en sus respuestas, el norte tendrá que apartarse progresivamente de la resistencia e irse acercando a las fórmulas de coopción y transacción.

La búsqueda de fórmulas de transacción dentro del marco de la diplomacia multilateral en una comuniclad internacional en que el poder se encuentra más disperso que nunca es la base del segundo punto de vista importante que tiene el norte sobre el conflicto norte-sur: el enfoque multilateral que persigue el consentimiento colectivo. Como dice el profesor Dahrenclorf: "El número de actores es grande; el graclo de cohesión, pequeño; la definición de la situación, imprecisa, vaga ... Si bien se está difundiendo un punto de vista pesimista sobre las organizaciones y conferencias internacionales... de hecho este método de abordar los conflictos internacionales adquiere cacla vez mayor importancia... habrá más conferencias"ss. No porque se pueda estar seguros de que unas 140 "naciones" puclieran llegar a ponerse de acuerdo sobre la solución a los problemas globales, sino simplemente porque no hay alternativa. Sin embargo, lamentablemente hay falta de liclerazgo constructivo de no ser por la posible excepción de un campo, que es muy polémico.

Este campo tan polémico es el tercer punto de vista clel norte (en realidad, esencialmente de los Estados Unidos) sobre la cuestión norte-sur. Se trata del criterio de la equidad. Como se sabe, está muy vinculado con la estrategia mediante la cual los Estados Unidos tra$\tan$ virtualmente de reafirmar su liderazgo en los asuntos económicos mundiales después de Vietnam y Vatergate, impartiéndole a su

37 R. Hansen, op. cit., pág. 29.

ss Ralph Dahrendrof, "International Power: A European Perspective", Foreign Affairs, agosto de 1977, pág. 81. 
política exterior un mayor sentido de justicia e intención moral. No obstante, el criterio de la equidad comprende preocupaciones muy variádas y a menudo contradictorias. Para los del norte, lo que interesa son las consideraciones de equidad cl=niro de los propios paises en desarrollo o, como variante, los derechos humanos. Para el sur, la cuestión de la equidad se relaciona con lo que se percibe como un modelo injusto de distribución del ingreso entre paises, consecuencia del actual "oxden" internacional. Ante las exigencias de los países menos clesarrollados de que se establezca un nuevo orden económico internacional que ponga de relieve la cuestión de la equiclad los liberales del norte responden que, de aceptarse las exigencias es posible que influyan poco o nada en la discribución clel ingreso, cle la riqueza o de las oportunidades dentro de los países menos clesarollados y que esto debería ser lo que más debiera preocuparles ${ }^{39}$. Como la mayoría de los grupos dominantes de los paises-en desarrollo consideran que esta cuestión no es negociable y que es un asunto exclusivamente interno, lo más probable es que le llegue a un punto muerto, a menos que el interés del norte llegue a verse como una tendencia irreversible (cosa que aún no ha ocurrido) y el diálogo norte-sur llegue a una delínición recíprocamente satisfactoria de la desigualdad "aceptable" y de los derechos humanos "mínimos".

En los intentos por evitar: este hueso duro de roer, el norte acaba de proponerse un cuarto criterio.

Este cuarto criterio no considera las diferencias de ingreso y su evolución, sino con la extrema pobreza. Es el punto de vista basado en las necesidades humanas básicas que se ocupa del terrible destino de alrededor de mil millones de personas, casi $25 \%$ de la población mundial, que viven en condiciones miserables. En principio, todos son contrarios a la miseria extrema. Sin embargo, la preocupación por ella plantea la misma clase de problemas del criterio anterior: el llamado problema de la "élite interna". Como observó Hansen (a Carter): "No se puede elaborar ni llevar a cabo ningún programa para eliminar la extrema pobreza a menos que las élites gobernantes y el sistema político de un país se encuentren suficientemente comprometido a ello. No hay volumen de recursos extranjeros que pueda superar la resistencia o la indiferencia interna al logro de este objetivo" 40.

Resumiendo este breve esquema de los puntos de vista dominantes en el norte: dos de ellos (el criterio de que la "unidad del sur

* Para una profundización de este poderoso argumento (en los Estados Unidos) por un economista que en la actualidad se encuentra a la vanguardia de la polf́tica económica exterior estadounidense, véase $R$. Cooper, "A New International Economic Order for Mutual Gain", Foreign Policy, número 26, segundo trimestre de 1977.

${ }^{2} \mathrm{R}$. Hansen, op. cit., pág. 34. 
no perduraxá" y el "enfoque multilateral global") pueden conducir a los países del norte a opciones de política que son esencialmente una continuación de las políticas actuales con cambios marginales ad hoc para adaptarse a exigencias que no pueden resistirse en forma efectiva, como en el pasado. Los otros clos puntos de vista, de la "equidad" y de las "necesidades básicas", tratan cle trasladar la responsabilidad del actual funcionamiento insatisfactorio del orden económico internacional (según sostienen los países menos desarrollados) más que nada a las propias políticas internas, o a los sistemas políticos de los países menos desarrollados. lis muy posible que la siluación se convierta en una especie de "diálogo de sordos", a menos que se llegue oportunamente a algún acuerdo básico sobre el progxama y sobre algunas perspectivas de largo plazo, tanto en el norte como en el sur. Los próximos párrafos se ocupan de los efectos que podrían tener estos puntos de vista del norte, y las tendencias estructurales del norte en las economías periféricas, con especial referencia al Brasil. A nuestro juicio, todo programa de futuras políticas de investigación en materia de relaciones económicas internacionales - tanto en el Brasil como en otras partes- debe comenzar por comprender los cambios estructurales clel mundo y los actuales puntos de vista del norte. Después de todo, aunque la iniciativa provenga del "sur", la respuesta del norte es lo que configurará los arreglos futuros.

Los llamados puntos de vista del sur sobre las cuestiones implícitas en la estructuración del nuevo orden económico internacional, están dominados por el deseo de obtener el control de recursos reales adicionales, de manera de acelerar el proceso de desarrollo de los países menos desarrollados. Is posible que estas transferencias de recursos reales entrañen "financiamiento en cuenta corriente" (a través de variaciones de los precios, de asistencia o de incumplimiento en el pago de la deuda externa) o "financiamiento en cuenta de capital" (a través de endeudamiento o de disminución de las reservas). Todos los países menos desarrollados, tanto los denominados "comerciales" como los que dependen de la ayuda, "11 preferixían que las transferencias de recursos reales requeridas tuvieran financiamiento de cuenta corriente, en especial a través de variaciones de los

a "Son pafses en desarrollo comerciales aquellos que ordinariamente ticnen acceso al crédito de los bancos comerciales. Como se sabe, la mayoria de los pafses menos desarrollados no miembros de la opep dependen principalmente de la asistencia externa, ya que no están en condiciones de obtener muchos créditos bancarios. A fines de 1976 nueve países "comerciales" (Brasil, México, Corea del Sur, Taîán, Filipinas, Argentina, Perú, Colombia e Israel) representaron más de $80 \%$ de la deuda pendiente bancaria de los países menos desarrollados. Véase David O. Beim, "Rescuing the LDcs" Foreign Affairs, julio de 1977, pp. 718 a 719 . 
precios 42 , ya que esta clase de financiamiento no entraña una transferencia contraria en el futuro, como lo hace el financiamiento en cuenta de capital. Lo más probable es que en esta cliscusión los paises comerciales y los que dependen de la asistencia formen un frente común e insistan con toda razón en que los países avanzados no pueden seguir siendo internacionalistas en materia de finanzas e inversiones y cada vez más proteccionistas en lo que respecta al comercio.

Donde seguramente no se formará un frente común es respecto de las cuestiones relacionaclas con el financiam.ento en cuenta de capital a través del endeudamiento en los mercados internacionales de capital. En este caso, lo más probable es que surja una marcada división entre los países comerciales y no comerciales, como ya ha sucedido en Manila, Nairobi y en las reuniones de la Conferencia de Cooperación Económica Internacional en París. Los países comerciales están muy conscientes de la necesidad de asegurar la permanente disponibilidad de financiamiento externo (aparte del incremento acelerado del comercio mundial), debiclo a la creciente merma cle divisas que entraña el servicio de la deuda. Por lo tanto, lo más probable es que rechacen cualquier propuesta "radical" de incumplimiento, de los pagos, mora de los mismos o renegociación cle la deuda, y optarán por solicitar nuevos préstamos ${ }^{43}$. Como se observó en el capítulo anterior, en el caso del Brasil (y de la mayoría de los países menos desarrollados y de mayores ingresos) el problema no es la inminencia del incumplimiento o de la renegociación, sino la disiribución de la carga del ajusie interno.

A mi juicio, éste es quizá uno de los campos de investigación más importantes y prometedores de cualquier programa de relaciones económicas internacionales de un país o región determinados: las repercusiones de una "estrategia" permanente de desarrollo hacia afuera en lo que respecta a la distribución interna del ingreso y a la naturaleza de los regímenes polílicos conexos. Pese al esclarecedor trabajo realizado por Cardoso y D'Donnel, por ejemplo, queda mucho por hacer en estos campos, en especial en materia de análisis comparado. En la actualidad se aprecia cada vez más el hecho de que el análisis debería centrarse en la naturaleza y' en la base social

2 No sólo los precios de los productos búsicos de las exportaciones de los patses menos desarrollados. La persistente inflación mundial reduce la carga real de la deuda, pero obviamente ésta no es una solución adecuada pára el problema.

* Como expresó con razón David Beim, la diferencia entre renegociar la deu. da y obterier un nuevo préstamo "es prácticamente metafísica. Los principios económicos son los mismos -el dinero se paga más adelante y no ahora-. Lo que difiere en la parte sicológica la renegociación es una confrontación, un reconocimiento de fracaso, una catars:s emocional, nientras que un nuevo préstamo significa seguir haciendo negocios como siempre". D. O. Beim, "Rescuing the LDSs", Foreign Affairs, julio de 1977, pág. 723. 
del Estado (y de las políticas estatales) de las sociedades menos desarrolladas. Por curioso que parezca, cualquier programa de relaciones económicas "internacionales" debe pasar por un análisis de la llamada "cuestión del Estado".

Ya se mencionó otro campo de investigación importante y prometedor y se relaciona con las perspectivas asimétricas y los intereses contradictorios que se encuentran dentro del mundo menos desarrollado. No hay que restarle importancia a estas asimetrías y contradicciones. En realidad, como se ha visto, el norte cuenta con ellas. Después de todo, sólo diez países menos desarrollados semiindustrializados representan casi $185 \%$ de la deuda externa (bancaria) total. Sólo diez países semiindustrializados representan más de $80 \%$ de las exportaciones totales de manufacturas de los países menos desarrollados. Todas las discusiones y dificultades que plantea el comercio entre los países menos desarrollados como alternativa al creciente proteccionismo del "norte" se malogran hasta cierto punto por el hecho de que en cada región del mundo en desarrollo sean probablemente dos o tres países los principales beneficiarios de los acuerdos comerciales regionales ${ }^{44}$. Es probable que los estudios sobre la relación entre el poder nacional y la estructura del comercio exterior -iniciados por Merschman hace más de 30 años- reaparezcan en el programa como temas muy interesantes y cuyo estudio se considera muy necesario.

Como es natural, cualquier programa de esta naturaleza debe incluir un cuidadoso examen de las empresas transnacionales, en especial ahora que está quedando de manifiesto que la mayoría de los países en desarrollo aumentarán de modo creciente la vigilancia de sus vínculos de comercio exterior y financieros, incluso a medida que procuren ampliar estos vínculos. Lo más probable es que en los principales países menos desarrollados se endurezcan las condiciones de negociación entre las empresas transnacionales y el Estado (o las empresas estatales) y a mi juicio, mucho más que estudios generales sobre las empresas transnacionales y sus efectos o estudios generales sobre la posible reacción del Estado firente a ellas, o ambos, lo que se necesita es un conocimiento mucho más profundo de los mercaclos invisibles internalizados por la mayoría de las empresas transnacionales, de los cuales los visibles a menudo son anexos insignificantes. Después de todo, los argumentos conservadores en favor de los "mercados libres" siempre han dependido de que se reduzca al mínimo el conocimiento de la forma en que efectivamente operan los mercados. Uno de los puntos importantes del programa deberían ser los estudios sobre las operaciones de los mercados imperfectos. En

« Véase Sir A. Lewis, Aspects of Tropical Trade, Conferencias Wicksell, 1969, para una profundización de estos puntos. 
definitiva, el argumento de los países menos clesarrollados en favor de la reorganización del orden económico mundial depende de que existan mercados internacionales imperfectos que los perjucliquen.

Al respecto, y para concluir esta sección, convendría recordar que hace casi medio siglo Lord Keynes defendió su argumento -a menudo citado- en faror de la autosuficiencia nacional en los siguientes términos:

"Las ideas, los conocimientos, el arte, la hospitalidad, los viajes, son cosas que por su naturaleza deberían ser internacionales. Pero hay que permitir que las cosas se hagan en casa siempre que ello sea razonable y convenientemente posible $y$, sobre todo, las finanzas deberían ser fundamentalmente nacionales".

mirando hacia atrás y a primera vista, la afirmación de Keynes parecía insatisfactoria: tiene demasiadas salvedades y data históricamente del peor año de la gran crisis (1933). Estas no eran con exactitud las ideas contenidas implícitamente en la expansión y consolidación del imperio colonial británico. Aclemás, esta clase cle icleas no caracterizaron el proyecto internacionalista relativamente exitoso de reorganizar el mundo capitalista bajo la hegemonía estadounidense después de la Segunda Guerra Mundial. Sin embargo, el fracaso del arreglo político de la postguerra a comienzos de los años setenta volvio a poner en el tapete algunas cuestiones que la historia parecería haber sepultado. Entre ellas, algunas de las planteadas por Keynes a comienzos de los treinta. Como es natural, el mundo de los años setenta es bastante distinto, pero más importante que observar hasta qué punto los países menos desarrollados han estado discutiendo la confianza colectiva en el esfuerzo propio, es recordar que las observaciones de Keynes apuntaron a lo esencial: la renovacla importancia de las opciones politicas en períodos de crisis económicas y de negociaciones para lograr nuevos arreglos "económicos" internacionales. En la actual situación y perspectivas económicas mundiales vale la pena prestar alguna atención a la antigua sugerencia de Keynes. Después de todo, cada vez queda más en claro que los patses periféricos no deberían -y no podrían- reproducir los modelos de acumulación de capital orientada al consumo privado que predominó en el centro en los últimos decenios.

\section{III}

Resumiendo el análisis anterior, me atrevería a decir que, en el peor de los casos, cualquier programa de investigaciones futuras sobre el tema de las relaciones económicas internacionales del Brasil tendría que: 
a) Insistir en la necesidad de consiclerar los problemas actuales y futuros dentro de una perspectiva histórica. Entre otras cosas, porque evaluar cuiclaclosamente las variaciones de largo plazo de la estructura de la economía mundial -y del poder mundial- es de fundamental importancia para un país semiindustrializado que ha llegado tan lejos como el Brasil en su articulación con el mundo capitalista a través del comercio y de las inversiones. Por desgracia, salvo por la influencia de la Comisión Económica para América Latina, en el Brasil prácticamente no ha existido la costumbre de analizar -y ni siquiera de seguir de cerca- los sucesos mundiales desde un punto de vista brasileño o latinoamericano. Es necesario ampliar cuanto antes en el Brasil la comunidad académica -y asimismo la integrada por los medios gubernamentales- orientada hacia la evaluación de la economía internacional.

b) Como las tendencias económicas y tecnológicas, por cuidadosamente que se estudien, no determinan los resultados futuros, es preciso analizar en forma mucho más explicita la politica internacional e interna (y sus relaciones). Como esperamos haber sugerido, esto exige seguir de cerca y evaluar las actuales percepciones, puntos cle vista y principales opciones del norte y del sur. Porahora el plano de discusión de estas cuestiones en el Brasil es demasiado superficial y no se vincula con las cuestiones planteadas más arriba en el apartado a), sino que se limita a un grupo de funcionarios gubernamentales aislados. Para un país con pretensiones de gran potencia y que ha de convertirse en potencia nuclear, el hecho de que público que critica la política externa sea tan limitado debería ser motivo de preocupación. Para que surjan opciones en materia de política extema brasileña viables desde el punto de vista político es necesario que se amplie la participación informada.

c) Como país clave de América Latina, región del mundo en que la influencia de los Estados Unidos va en manifiesto descenso -como sucede en otras partes del mundo-, uno de los puntos más importantes del programa es la relación del Brasil con los países hispanoamericanos. Lo más probable es que el papel de América Latina como región más avanzada del mundo menos desarrollado revista cada vez mayor importancia en la configuración del actual orden económico mundial. En realidad, parece extremadamente importante revitalizar la tradición de la CEPAL de reflexionar acerca de la región latinoamericana dentro de un marco internacional y continuar el esfuerzo por fortalecer los vínculos que nunca han sido tan fuertes como debieran. Después de todo, la región en su conjunto podría ampliar las estrechas opciones que confronta cada pais individualmente.

d) La preocupación por América Latina como región no debería per- 
mitir que nos olvidáramos de la situación más bien singular del Brasil dentro de la economía y de la política mundiales. En realidad, como uno de los paises situados en el "umbral" (para utilizar la expresión de Dahrendorf), lo más probable es que Brasil tenga que elegix entre aceptar ser objeto de coopción por el centro o tratar de ejercer algún tipo de liderazgo entre los países del "sur". ¿O tratar de hacer ambas cosas? Uno de los puntos importantes de un programa de estudios comparados debería ser el estudio de lo que es especifico en el caso brasileño. La convergencia de intereses coexiste con algunos conflictos de largo plazo que deberían definirse más claramente.

e) Analizar la economía y política brasileña desde un punto de vista internacional entraña realizar un análisis cuidadoso de la llamada "cuestión del Istado" en el Brasil: su naturaleza, su base de apoyo social, su réginzen inestable y, cle manera muy especial, las limitaciones impuestas a las principales opciones de política interna por la mayor integración con el comercio internacional y' con los mercados de capital. Debería darse prioridad a la investigación sobre la naturaleza de estas limitaciones y la relación entre las políticas económicas externas y sus repercusiones internas en materia de distribución.

f) Por último, como esperamos haber sugerido al analizar los llamados puntos de vista del norte, no toclos ellos entrañan o imponen restricciones a las opciones internas de los países menos desarrollados. Por ejemplo, podría estimarse que los criterios de "equidad" o de "necesidades básicas" son ingenuos, que carecen de perspectivas a largo plazo, que se contraponen a los valores capitalistas o que se idearon con otros fines. Cualesquiera recelos que pudieran abrigarse, los criterios pueden y deben utilizarse para apoyar nuestros propios esfuerzos internos para construir una sociedad menos represiva. 